\title{
El complejo periplo intelectual y político de Dora Mayer \\ Una aproximación desde la Sociología de los intelectuales en América Latina
}

Tirso M0LINARI

Susana ALDANA

\section{RESUMEN}

El artículo muestra el devenir intelectual y político de Dora Mayer desde el indigenismo militante hasta unas simpatías por el fascismo urrista.

The complexintellectual and political journey of Dora Mayer An approach from the sociology of intellectuals in Latin America ABSTRACT

This article shows Dora Mayer's intellectual evolution from militant indigenism to some affection for Urrista fascism. 


\section{Dora Mayer y su condición de intelectual}

A

cceder al periplo intelectual de Dora Mayer supone acceder a un personaje intensamente peculiar en relación a las tendencias intelectuales expresadas en la Lima de la primera mitad del siglo XX. Dora Mayer iba a contracorriente en casi todo. Era extranjera, siempre fue «bastante mayor», era mujer, era ampliamente ilustrada, era polígrafa, era indigenista, era contestataria, carecía casi de parentescos, era explícita, no estaba en el campo académico-universitario ni tampoco en el literario-formal. Además, hizo de un «amor imposible» una suerte de emblema público. Ella dejó, así, toda una huella contundente en la vida política del país.

Como «productora de ideas», siguiendo a Coser y a Bobbio ${ }^{1}$, su existencia no se limitó al «campo intelectual» en sí. Campo en el cual, a su vez, tomando a Bourdieu ${ }^{2}$, tenía una presencia legitimada desde el panorama periodístico y político pero no necesariamente académico. Said ${ }^{3}$ también resulta un interesante referente, pues aunque Dora Mayer no fue una intelectual propiamente exiliada y expatriada, las condiciones históricas que la rodearon determinaron que ella tuviera una cultura dentro de otra cultura lo cual la hizo hasta cierto punto una mujer marginal en el país en el cual recaló desde la infancia y asumió intensamente. Y en el Callao y también en Lima, el «mercado de almas» al que se refiere Pablo Macera ${ }^{4}$ vivió toda su vida y negándose rotundamente a adoptar todos aquellos códigos de la construcción social femenina de entonces.

Por al contrario, Dora Mayer asumió con Intensidad su opción transgresora y se desenvolvió con mucho aplomo en todos esos contextos masculinos en los que se desempeñó intelectualmente. Desde la matriz ideológica que asume, despliega muy explícitamente aquella función de «gestora de sentido». Precisamente, Dora Mayer antes que nada fue intelectual; su perspectiva iba más allá del acontecimiento y de la coyuntura, se orientaba a largo plazo. Así, su afán de «creación de sentido» se proyectaba con intensidad a través de su obra cuyo eje era su empecinado afán de «equidad» y de «justicia social» que desbordaba incluso a su tenaz combate al gamonalismo y a su consecuente y apasionada apuesta por la reivindicación indígena. Ella desplegó su acción, tan cargada de racionalidad y también de pasión, entre el «largo plazo» intelectual y el «corto plazo» de lo político y bajo aquellos parámetros que Weber

Bobbio, 1988.

Bourdieu, 2000.

Said, 1996.

Macera, 1992.

\section{8/ REVISTA DESOCIOLOGÍA 25}


tipificaba como la «ética de la convicción» y la «ética de la responsabilidad» respectivamente 5 .

Dora Mayer era, sin ninguna duda, lo que en su contexto sociocultural y de tiempo solía ser un intelectual: «un generalista». Su inquietud era el panorama; era primero el bosque antes que el árbol. O siguiendo a I. Berlin, podríamos considerarla metafórica-mente más cercana al zorro que al erizo. Para entender ese lado político-intelectual, des-conocido de su trayectoria, ese lado oscuro y complicado que responde a un carácter más o menos ambiguo, que todo sujeto en su condición de actor supone, se hace necesario acceder a la sociología comprensiva de Weber, al psicoanálisis, a los interaccionismos de Mead y de Goffman así a la teoría de la estructuración de Giddens. Más aún, si nuestra reflexión apunta a una intelectual en un contexto tan complejo de relaciones sociales y políticas como fue el Perú y la Lima de su tiempo.

De esa manera, más que un ánimo de desmitificación de un icono intelectual «progresista» e incluso, «feminista», tal como aparece la huella de Dora Mayer en el panteón ideológico establecido del país, se muestran las pistas de la ambigüedad de una intelectual que, no obstante jamás abandonó su vocación de rectitud y consecuencia frente a sus ideales de «justicia social», «equidad» y de «reivindicación indígena» pero que, a su vez, se deslizó por caminos que precisamente no eran los que la ortodoxia progresista indicaba: el camino de Mariátegui o el de Haya de la Torre. Dora Mayer no optó ni por el uno ni el otro. Más bien, se desplazó por el oscuro del sanchecerrismo y lo que es más dramático se vinculó en 1934 con su versión fascista luego del asesinato de Sánchez Cerro. Pero, inevitablemente, el vínculo con la derivación fascista del sanchecerrismo sí problematiza y contrasta con el acercamiento que tuvo no sólo con Mariátegui sino con el propio Pedro Zulen quien ya en 1919 simpatizaba con la revolución rusa.

Sin embargo, es también de suma importancia observar que Dora Mayer desde su «militancia» en la Sociedad Pro-indígena, entre 1909 y 1916, no volvió a «militar» en ninguna otra organización política-intelectual, filantrópica o simplemente política. Más allá de su tenaz participación en aquella organización indigenista, Dora Mayer fue una intelectual que optó por la autonomía, que generó una amplía y polémica producción bibliográfica y que ejerció con sistematicidad la colaboración periodística. De esa manera, desde 1916 hasta inicios.de la década de 1930 y aunque su indigenismo fue el eje de su reflexión política, no se incorporó orgánicamente ni al socialismo marxista ni al aprismo

$5 \quad$ Weber, 1998. 
ni a ninguna otra asociación política. Sus cercanías intelectuales con José Carlos Mariátegui fueron, desde su indigenismo radical, más de compromiso intelectual que estrictamente políticas. Cercanías no exentas de asperezas y críticas ${ }^{6}$.

De alli que no es tan sorprendente, así, su posterior simpatía con el sanchecerrismo y con la derivación fascista de aquel después de 1933, pues si algo fue objeto de su más contundente crítica política fue el régimen de Leguía. Precisamente el sanchecerrismo hizo de la más agresiva crítica, política y moral al régimen de Leguía, una suerte de estandarte de su acción. Además en el sanchecerrismo, e incluso en su derivación fascista, al menos como retórica, el discurso indigenista estaba de alguna manera presente ${ }^{7}$. Así también, uno de los principales líderes y luego su secretario general fue nada menos que Abelardo Solís, ideólogo de la comunidad campesina, ex contertulio de Mariátegui y hombre en lo básico, identificado con el indigenismo ${ }^{8}$.

De alguna manera, esa autonomía intelectual en Dora Mayer era también expresión de su ambigüedad política. No frente a los ideales de justicia social, de equidad y de indigenismo y otros que suscribía sino frente a la concreción política de los mismos. Pero es que Dora Mayer no es clara en cuanto a las salidas políticas. Su rechazo al gamonalismo, su rechazo al poder de los enclaves mineros explotadores del obrero de origen campesino, su rechazo a la tiranía «corrupta» de Leguía, etc., no suponía alternativas políticamente definidas en cuanto revolución socialista, democracia radical o dictadura autoritaria. Más bien su paulatina y tajante distancia frente al comunismo y su contundente rechazo al aprismo viabilizarán, sus simpatías con el sanchecerrismo y su colaboración periodística con el fascismo urrista en el cual, sin embargo, no consta ninguna huella de adhesión orgánica`. Posición que es bastante ambigua, así como ambigua fue su posterior actitud frente al nazi-fascismo al que criticará moralmente pero también avalará políticamente por «sus inicios» ${ }^{10}$.

Ese «lado oscuro» de Dora Mayer no fue secreto ni oculto pues siempre fue explícita, franca y directa en su pensamiento y en su acción. «Lado oscuro» que, como se ve, y bajo el carácter de esa ambigüedad, no constituía una contradicción profunda con sus propias convicciones, dado que éstas, y luego de la disolución de la Asociación Pro-indígena en 1917, eran más abstractas que político- prácticas. Más bien, aquel «lado oscuro» podría constituir una suerte de «desviación» intelectual más para la perspectiva establecida sobre

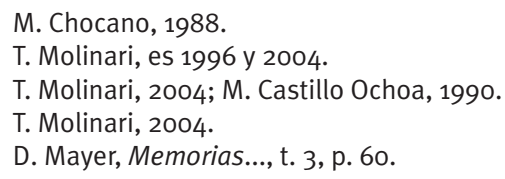


aquel «radicalismo», «progresismo» y «feminismo» desde el cual, estereotipadamente, aparece en el panteón ideológico establecido y el cual no repara en contextos, en fases ni en ambigüedades.

\section{Dora Mayen su obra y su acción en su trayectoria intelectual y política}

En el primer tomo de sus Memorias ${ }^{11}$, Dora Mayer, nacida en 1868 en Hamburgo-Alemania, indica que llega al Callao el 14 de abril de 1873, instalándose con sus padres en ese puerto y específicamente en la calle Ucayali. Allí, afirma Dora Mayer, vive durante 58 años y por motivos de salud se muda a Lima recién en 1931. Su vida personal e intelectual transcurre entre el Callao y Lima.

En sus Memorias indica que su instrucción fue básicamente familiar. Su padre asumió el rol de preceptor, con más amabilidad que rigidez, bajo pautas de una educación libre y bastante moderna para la época. Todo esto deja una huella que hizo de Dora una mujer cargada de curiosidad, actitud crítica y enorme vocación autodidacta. En sus Memorias se evidencia también que su padre, personaje entre comerciante, rentista y aventurero, y su madre, mujer cultivada y de cierto abolengo, a veces flexible y a veces severa, salen de Alemania por motivos personales pero también disconformes por el proceso bismarckiano de unificación alemana.

Sus Memorias presentan que, sin excesivas ortodoxias, los Mayer mantienen en el Perú, en el ámbito familiar y amical, la fe protestante-luterana. Fe protestante que integró, parcial y complejamente, la Dora intelectual y librepensadora.

Esta impronta familiar contribuyó a hacer de Dora un personaje iconoclasta, diferente, que ella asumió con intensidad. Bajo este panorama y desde su prolija humanista instrucción, se encaminó paulatinamente, con mucha pasión a la actividad intelectual, principalmente desde la colaboración periodística y el ensayo. A través de ellos, el compromiso político-crítico se convierte en el eje de sus textos. Precisamente el horizonte de su producción bibliográfica es bastante amplio y diverso y muestra una intelectual que fue, antes que nada escritora y específicamente ensayista. En este último quehacer, el ensayo, su producción fue muy amplia e intensa como se aprecia por la imprescindible relación que se coloca a continuación:

- Estudio sociológico (para el IV Congreso. Científico Panamericano de Santiago de Chile. Callao 1908). 
- La conducta de la compañía minera de Cerro de Pasco (Callao, 1914).

- El indígena peruano a los cien años de república libre e independiente (Lima, 1921).

- Un libro sobre Jesucristo. Crítica de la obra la «Locura de Jesús» (Lima, 1921).

- La China silenciosa y elocuente: homenaje a la colonia china en el Perú (Lima, 1924)

- El indígena y su derecho (Lima, 1929).

- Zulen y yo. Testimonio de nuestro desposorio (Lima, 1928).

- El Oncenio de Leguía (Callao, 1932).

- Temas actuales en el Perú y el mundo (Lima, 1937).

- El indígena y los congresos panamericanos: vicios viejos y miradas nuevas en el Perú y Suramérica (Lima, 1938).

- Estudios sociológicos de actualidad (Colección de artículos. Lima, 1950).

- Más aún, hubo libros de Dora Mayer que fueron publicados póstuma y muy tardíamente:

- La historia del mundo en un cascarón de nuez (s.f.) (UNMSM, Lima, 1953).

- Memorias de Dora Mayer de Zulen. Tres tomos (UNMSM, Lima, 1992).

A todo esto hay que agregar el papel que asumió como Directora y fundadora de la revista indigenista el Deber Pro-indígena, órgano de la Sociedad ProIndígena. En esta revista auroral del indigenismo peruano están sus múltiples y militantes artículos indigenistas, publicados entre 1912 y 1917. También es del caso mencionar su importante colaboración en la revista Amauta y desde la cual, en 1926, hace todo un balance de lo que fue la Asociación Pro-Indígena.

¿Cómo se puede tipificar a Dora Mayer frente a ese vasto panorama intelectual, crítico y contestatario?, ipopulista o revolucionaria, bajo la tipificación de E. Shild? La respuesta es difícil pero más inclinada al «populismo» dado su elogio y su fe en las multitudes populares y especialmente en los indígenas-campesinos. A pesar de que estuvieran bajo los límites más o menos paternalistas del indigenismo, que sin embargo, en Dora Mayer paulatinamente derivaron en un discurso pro-autonomización indígena-radical ${ }^{12}$.

«Revolucionaria» no era, si entendemos esto desde el cambio políticosocial radical por la fuerza. Además, como se dijo anteriormente, sus distancias con el comunismo y con el Apra eran contundentes. Su indigenismo, su defensa del obrero y su clamor de justicia social, como se verá, no anclaban en un

Kapsoli, 1980.

\section{2/ REVISTA DE SOC1OLOGÍA 25}


panorama radical de «lucha de clases» ni de «toma de poder», etc., sino más bien en ideales y en búsquedas prácticas de reforma social. Sin embargo, frente al latifundio no hubo concesiones y la salida fue su erradicación y la devolución de las tierras a los campesinos, en particular a las comunidades ${ }^{13}$.

Empero, hubo momentos en que Dora Mayer, en función a sus vínculos personales con Pedro Zulen, estuvo más o menos cerca a las ideas del socialismo revolucionario y bajo el impacto de la revolución bolchevique. Esto fue en 1919, en el contexto de su viaje a Jauja y luego de la disolución de la Asociación Pro-indígena. De allí, también su acercamiento posterior a Mariátegui ${ }^{14}$.

Frente a todo esto, es muy importante presentar lo que la propia Dora Mayer, en sus Memorias, dice de manera muy contundente al respecto:

... se nota que los izquierdistas me han tenido por suya pero que a veces los he decepcionado porque he visto en ambos lados cualidades apreciables. No he sido partidaria incondicional y extremista, no me regocijo en luchas sino en buenos acuerdos, en buen entendimiento. A veces, el uno no sabe apreciar las virtudes peculiares del otro y mucho menos logra ver la viga en el ojo propio mientras descubre la paja en el ojo ajeno. Soy de la paz, deseo armonía y no encono recíproco. Deseo que baje el tono de las discusiones polémicas y dé el resultado de una humanidad en columbración... ${ }^{15}$

Con bastante énfasis afirma su «neutralidad política» también en sus Memorias, de la siguiente manera:

... yo no soy personalmente ni derechista ni izquierdista sino neutral. Juzgo en ambos lados lo que me parece bueno o malo, motivado e inconveniente. La prueba está que he colaborado abundantemente en periódico de ambas especies [...] prefiero ser imparcial ${ }^{16}$.

Dora Mayer estaba absolutamente alejada de lo que Singer clasifica como «intelectual mandarín». Más bien se acerca a lo que tal autor tipifica como «intelectual comprometido», por la intensidad de su vínculo a la política desde el debate público. Empero, era un compromiso sin la especificidad definida de un partido - la ambigüedad aludida anteriormente - sino más con la «justicia social» y la «defensa del indígena», entre otros. Una visible

\footnotetext{
Kapsoli, 1987.

Kapsoli, 1987.

D. Mayer, Memorias..., t. 3, pp. 139-140.

D. Mayer, Memorias..., t. 3, pp. 90-91.
} 
caracterización de esta intelectual como ideóloga más que como experta, si seguimos la tipificación de N. Bobbio.

Siguiendo la antigua consideración de A. Smith, del ideólogo como justificador y normativista, Dora Mayer no sólo ponía sangre a sus ideas (a lo Nietzsche) sino que se movía con la mayor amplitud normativa del «debe ser» y de la más estricta justificación de los proyectos contestatarios que asumía. Asimismo, su visión «todista» la llevaba por una suerte de humanística diversidad temático-crítica.

Si bien su momento de mayor intensidad indigenista fue entre 1909 y 1917 , e incluso la temática de la reivindicación indigenista la asumió con pasión hasta los primeros años de la década de 1920, sus intensas preocupaciones intelectuales entre dichos años, los de 1930 y hasta su muerte en 1959, se amplían. Aparecen la discusión religiosa-cristiana, las reflexiones sobre la China y la problemática de la inmigración y de la colonia china en el Perú, así como temas internacionales y peruanos diversos. Desde allí, hay que reparar en la implacable crítica al régimen autocrático de Leguía, publicada en 1932, desde la cual tiende aquellos complicados y oscuros puentes con el sanchecerrismo.

Obra que sólo culmina con su fallecimiento en 1959, pues meses antes de morir y a sus 91 largos años, Dora Mayer escribe sus tres tomos de Memorias, llena de lucidez y entusiasmo vital.

Sin embargo, la huella del indigenismo, aunque ya morigerado, de aquellos aciagos años de 1930, está presente a lo largo de su tan agitada vida intelectual y personal. Agitada vida en donde, incluso, hubo espacio para ventilar públicamente un episodio íntimo pero bajo el marco de la vocación y el compromiso indigenista con el filósofo y bibliófilo Pedro Zulen. Sobre él, publica en 1928, su mencionado texto «Zulen y yo, testimonio de nuestro desposorio» donde da cuenta de su apasionado amor por dicho personaje.

La importante dimensión intelectual y política de la vida de Dora Mayer se expresa, con especial énfasis, durante su período de activa militancia indigenista, en la Asociación Pro-Indígena. Asociación de singular importancia en la defensa del indígena peruano, principalmente frente al gamonalismo y la explotación minera y que sabemos, por Kapsoli, que existió entre 1909 y 1917. La revista de la asociación, el Deber Pro-Indígena, dirigido por Dora Mayer, como se mencionó, se editó desde octubre de 1912 hasta diciembre de 1917 y tuvo 51 números publicados. Una organización, reivindicativa y de defensa del indígena peruano, con sede en Lima, que tuvo como dirigentes a un grupo de destacadísimos intelectuales conformado, junto a Dora Mayer, por Joaquín Capelo, Pedro Zulen (que fue el secretario general), Vitaliano

\section{4/ REVISTA DE SOCIOLOGÍA 25}


Berroa, Emilio Segui, Rómulo Cúneo Vidal, Daniel Alomía Robles y Abelardo Gamarra.

Hay que enfatizar en el hecho que Dora Mayer alterna, no obstante el contexto «masculino-céntrico», con aplomo y de «igual a igual» con aquel grupo de destacados intelectuales, varones todos y bajo condiciones de estricta reciprocidad intelectual, dada su personalidad y su actitud protagónica. Así, en el estudio de Kapsoli se puede observar la dirección estratégica que tuvo esta intelectual en la directiva de la Asociación Pro-Indígena asumiendo la dirección de publicaciones y de la revista de la asociación. Así, la junta directiva en 1912 tuvo la siguiente conformación:

\begin{tabular}{|c|c|}
\hline $\begin{array}{l}\text { Joaquín Capelo, presidente } \\
\text { neral }\end{array}$ & Pedro Zulen, secretario ge- \\
\hline Vitaliano Berroa, tesorero - & Dora Mayer, publicaciones \\
\hline Emilio Segui, bibliotecario- & Rómulo Cúneo, vocal \\
\hline Daniel Alomía Robles, vocal & Abelardo Gamarra, voca ${ }^{17}$. \\
\hline
\end{tabular}

El carácter de esa militancia indigenista de Dora Mayer, se presenta con elocuencia lo que en esos años la Asociación Pro-indígena supuso tanto en Lima como en el interior del país. Kapsoli señala:

La Asociación Pro-Indígena fue una institución polémica, condenada por el gamonalismo y la oligarquía, defendida por el pueblo y los amigos del indio. Los hacendados, los curas las autoridades y en general, los caciques locales, apostrofaron a sus miembros, ridiculizaron sus ideales y se enseñaron contra «los mensajeros indígenas» que acudían a la Asociación. Por su parte, jóvenes universitarios, profesionales liberales, dirigentes obreros y artesanos, se identificaron ella, se sumaron a su causa, le dieron vida entre 1909 y $1917^{18}$.

El propio José Carlos Mariátegui da su versión sobre la Asociación Pro-Indígena:

... sirvió para aportar una serie de fundamentales testimonios al proceso del gamonalismo, determinando y precisando sus tremendas e impunes responsabilidades. Sirvió para promover en el Perú costeño una corriente pro-indígena que preludió la actitud de las generaciones posteriores y sirvió sobre codo, para encender una esperanza en la tiniebla andina, agitando la adormecida conciencia indígena ${ }^{19}$.

\footnotetext{
17 Kapsoli, Op. cít, p. 12.

18 Kapsoli, Op. cít, p. 1.

19 Citado por Kapsoli, Op. cit., p. 2.
} 
Recorriendo las páginas del estudio de W. Kapsoli se nota la posición de la Asociación Pro-Indígena de crítica frontal al gamonalismo, a la explotación semiservil en el latifundio, al despojo de las tierras comunales así como el énfasis en la importancia crucial de la educación indígena y la necesidad imperiosa de la concreción de libertad y de justicia en el ámbito social andino. Mariátegui sintetiza el periplo de la Asociación Pro-Indígena, resaltando la contundente presencia de Dora Mayer y Pedro Zulen. Ambos aparecen, en los últimos años de la Asociación, sosteniendo con una enorme voluntad y fervor lo que fue quedando de la misma. Dice al respecto Mariátegui:

... su acción se redujo gradualmente a la acción generosa, abnegada, nobilísima, personal de Pedro Zulen y de Dora Mayer. Como experimento, la Asociación Pro-indígena sirvió para contrastar, para medir la insensibilidad moral de una generación y de una época. ${ }^{20}$

Precisar las ideas indigenistas y político-crítica de Dora Mayer nos permiten observar la agudeza de sus reflexiones y de sus críticas de carácter indigenista que incluso la llevan, más allá de su radical crítica al gamonalismo, al problema de lo que hoy vemos como dominación cultural. Como Chocano transcribe de Dora Mayer, ésta afirmaba lo siguiente:

son raros los casos en que los criollos de civilización europea sientan verdadera benevolencia y no lo miren como una especie de pesadilla nacional o como un instrumento burdo pero aprovechable para el desarrollo. ${ }^{21}$

A su vez, Dora Mayer es contundente con su identificación con el indio y la condición de éste de «prisionero en su propio país» que, en su radicalismo indigenista presenta:

... se habla de salvajismo de los indios y no del salvajismo de una sociedad que aprovecha de la última penuria de sus semejantes para proveerse de sirvientes. ${ }^{22}$

Frente al obrero, Dora Mayer relaciona su problemática con la del indígena y, a su vez, resalta tanto la mayor opresión del indígena y su condición mayoritaria en el país, desde lo cual considera la prioridad de la cuestión indígena. Dice Dora Mayer:

20 Citado por Kapsoli, Op. cit., p. 3.

21 M. Chocano, Op. cit., p. 6.

22 M. Chocano, Op. cit., p. 7.

\section{6/ REVISTA DE SOCIOLOGÍA 25}


... el problema del obrero y el problema del indígena es uno porque el indígena forma la inmensa mayoría de la población obrera en el Perú. Así lo han reconocido algunas personas de la clase obrera en Lima pero fuerza es decir, que en la práctica, se ha dejado notar sólo muy limitadamente un sentimiento de solidaridad de las asociaciones obreras urbanas con los trabajadores con los trabajadores más oprimidos de la república. ${ }^{23}$

Aquí, M. Chocano apunta a un elemento crítico de Dora Mayer frente a José Carlos Mariátegui y ya en el contexto de 1932, año en el cual publica su libro el Oncenio de Leguía, y ya bajo la aproximación al sanchecerrismo:

... desde ese punto de vista lanzará duras críticas a Mariátegui pues consideraba que éste buscaba «sovietizar» al Perú, dándonos un triste comunismo ruso por el valioso comunismo de nuestros primeros padres sudamericanos. ${ }^{24}$

Esta acotación de M. Chocano es clave para situar aquel «desliz» ideológico y político de Dora Mayer al sanchecerrismo y que posteriormente, llega a la colaboración con el periódico Crisol, órgano periodístico del Partido Unión Revolucionaria (PUR), ya fascista en 1934.

Retomando las ideas de Dora Mayer, durante el contexto de su «militancia» en la Asociación Pro-Indígena, su libro La conducta de La compañía minera de Cerro de Pasco, editado en 1914, constituye una importante evidencia de la relación entre su radicalismo indigenista con un pragmático nacionalismo anti-imperialista. Dice Dora Mayer:

... La compañía entró de lleno en las vías del fraude, el cohecho y la violencia. Nada tendríamos que decir de la fácil corrupción de los hombres de negocio, venidos aquí, si los pueblos anglosajones no se jactaran tanto de su superioridad moral sobre los sudamericanos. ${ }^{25}$

Libro de singular importancia no sólo por el estudio que efectuó sobre las formas de explotación del trabajador en aquella empresa minera norteamericana sino también por los prolijos y dramáticas testimonios que presenta. Asimismo, aquella relación entre el indígena-campesino y el proletario minero, es puesta de relieve por Dora Mayer, bajo los siguientes términos:

\footnotetext{
23 M. Chocano, Op. cit., p. 10.

24 M. Chocano, Op. cit., p. 10.

25 D. Mayer, La conducta, de la compañía..., p. 2.
} 
ningún argumento habla más en contra de la compañía del Cerro de Pasco que la inhumanidad de su conducta hacia los operarios indígenas que ocupa en sus labores [...] Los operarios se reclutan entre los operarios de la sierra que viven entregados a la agricultura y son traídos a veces desde largas distancias. Se preguntará corno se induce a estos hombres a abandonar sus pequeñas propiedades que les dan sustento para ingresar a las labores penosas y mal retribuidas de las minas. Pues mediante el aliciente de una cantidad de dinero que se les ofrece en forma de un adelanto bajo la condición de que vayan a las minas a reintegrar el valor con su trabajo. Este procedimiento se llama el enganche [...] Algún acreedor despiadado apremia al indio, viene el agente de las grandes industrias que buscan brazos y pone a su disposición de 50 a 150 y hasta 300 soles, lo hace firmar un contrato que sirve de instrumento para obligarlo a cumplir su nuevo compromiso y que le quita toda libertad mientras no se cancele la deuda con el patrón. Hay un medio de prolongar esta deuda mucho más allá de sus límites naturales, haciendo descuentos en el salario del trabajador por multas, gastos efectuados en las bodegas anexas a la negociación o introduciendo errores aritméticos en sus libretas. No faltan operarios que habiendo sido contratados por un par de meses en una mina no pueden moverse de ellas por un par de años o si salen alguna vez a visitar su tierra natal tienen que regresar a cancelar su cuenta porque la autoridad pública secunda a los empresarios en su reclamación por doquiera que el operario demandado se encuentre. La Cerro de Pasco Mining Co atrajo a su centro una multitud de operarios subiendo la tasa ínfima del jornal que regía entonces, un sol cincuenta centavos, pero no tardó en asociarse a los métodos de explotación que acabamos de describir y que constituyen el sistema de esclavitud por deudas, tan conocido, de las personas en países como Inglaterra que se interesan por la suerte de las razas oprimidas. ${ }^{26}$

Es destacable, más allá de su indigenismo, la contundente crítica política al régimen autocrático de Leguía que, al parecer, fue esencial en aquella sintonía que estableció Mayer con el sanchecerrismo. Los puntos más mordaces aparecieron en el mencionado libro El Oncenio de Leguía, editado en 1932 y enmarcado por los momentos más trágicos de la dictadura de Sánchez Cerro. Así:

... ninguna ley más abominable se ha dictado quizás en los cien años del estado que de la conscripción vial de 1920. Es una ley que declara a todo hombre nacido en el país, esclavo del estado y que pesa por supuesto, en la práctica, exclusivamente sobre el indígena, esclavo ya, a quien en vez de liberarlo se le remachan las cadenas [...] Leguía hizo y dijo siempre 
lo que más le agradaba a las gentes; su método fue como del cantinero que escancia sin reserva el alcohol al alcohólico. Leguía sació la sed de los enfermos de megalomanía, o sea de delirios de grandeza [...] Leguía, espíritu perspicaz y burlón, miró aquella descomposición oculta bajo una superficie que conservaba la apariencia de no variar; analizó todos los puntos vulnerables del edificio que pensaba derribar y ofreció a la Patria Nueva. Derribar instituciones democráticas carcomidas por la corrupción, cual por una polilla que entra en muebles añejos de sustancia ligera no hubo de ser difícil27.

Finalmente y volviendo al libro sobre el régimen de Leguía, publicado en 1932, aquel funesto año de la barbarie, M. Chocano nos da las pistas, quizás principales, para llegar a ese camino oscuro al que accede Dora Mayer en el contexto de sus simpatías con el sanchecerrismo. Desde allí, hará explícita su distancia política e ideológica tanto con Mariátegui como con Haya de la Torre lo cual nos servirá de puente para ubicar el carácter de su colaboración periodística con el Partido Unión Revolucionaria fascista, posteriormente y ya en 1934. Sobre la mencionada distancia, M. Chocano dice lo siguiente:

... esa carencia de principios, según Mayer, le dará a Leguía una gran facilidad para instrumentar todos los factores existentes a su alrededor. Y desde este punto de vista, ella considerará que la oposición promovida por Mariátegui y por Haya no fue auténtica ni independiente: Cuando toda lectura libera se haya perseguida a muerte por los esbirros del régimen, la revista Amauta de Mariátegui circula con pasaporte oficial y hecha todavía un tímido retoño, Labor, más apropiado que aquella revista para penetrar en las masas populares. La crítica Mariátegui, como hemos señalado antes, se fundaba también en que Dora Mayer pensaba que éste había confundido el socialismo con el indigenismo. Pero además de esto, su discrepancia es un signo de malentendido generacional ${ }^{28}$.

Luego de la publicación del libro El Oncenio de Leguía y que tenía que ser de especial agrado para el régimen ya dictatorial de Sánchez Cerro, Dora Mayer se vinculó con el sanchecerrismo, aunque en sintonía política pero no orgánicamente, a tal punto que llega a colaborar con el periódico Crisol en. 1934, tal como se mencionó. Veremos, posterior-mente, el carácter de tal colaboración.

Finalmente, si se sintetiza el periplo vital, intelectual y político de Dora Mayer, entre 1909 y 1932, se puede observar que entre 1909 y 1917 participa de manera militante en la Asociación Pro-indígena; en 1919, acompaña a un

27 D. Mayer, citado por chocano, Op. cit., pp. 10-12.

28 M. Chocano, Op. cit., p. 13. 
Pedro Zulen cada vez más radicalizado en Jauja; en la década de 1920 colabora en diversos periódicos (La Prensa, El Comercio, El Callao, entre otros) ${ }^{29}$ y amplía su panorama temático-crítico, manteniendo e incluso radicalizando su indigenismo en términos ideológicos. En este contexto, colabora con la revista Amauta, principalmente en 1926. Por último, canalizará su rechazo a la dictadura de Leguía a través de su simpatía con el sanchecerrismo con las consecuencias anticomunistas y antiapristas que eso supone.

\section{Dora Mayer y su colaboración con el periódico urrista-fascista Crisol}

Entrar a este punto, nos supone incursionar a aquel «lado oscuro» de la política peruana. Es decir, aquel «lado oscuro» que supuso el fascismo peruano en su versión post-sanchecerrista y desde el agresivo Partido Unión Revolucionaria dirigido por Luis A. Flores -enemigo apocalíptico y contundente y del comunismo - entre 1933 y 1939- Partido de arraigo multitudinario y que fuera el de mayor organización fascista y pro-corporativista de América Latina ${ }^{30}$.

Sin embargo, ya hemos visto que Dora Mayer nunca se definió como «izquierdista» y políticamente su compromiso fue con la «justicia social», la «defensa del indígena», etc., pero no con ninguna organización política en particular. De allí, su temprana «distancia» con Haya de la Torre y su posterior distanciamiento, en concreto, con las ideas de Mariátegui.

Y esa colaboración periodística con el fascismo post-sanchecerrista, es decir, con el periódico del PUR, Crisol, en 1934, no constituyó simplemente una ecléctica colaboración con un periódico de derecha, como pudo ser con un periódico de izquierda, como lo decía en sus Memorias y ya a los 91 años en 1959. No, en el contexto en que colabora periodísticamente con el urrismo estaba muy fresco aún el enfrentamiento político e ideológico, el cual había llegado a una situación extrema y donde la insurrección aprista de Trujillo en 1932, con sus graves secuelas en Huaraz y Cajamarca, había sido derrotada a sangre y a fuego, con miles de muertos y fusilados.

Dora Mayer asumió una clara decisión: entre el sanchecerrismo y el aprismo optó por el primero. De allí, aquella singular colaboración con el periódico Crisol y a tan sólo un año del asesinato de Sánchez Cerro. Y esa opción se puede apreciar diáfanamente por el carácter de su discurso presente en esa colaboración periodística; lo cual nos remite a reparar en el tipo de periódico

29 D. Mayer, Memorias..., t. 3, pp.140-152.

30 Molinari, 2004, passim.

\section{0/ REVISTA DESOCIOLOGIA 25}


y en el tipo de organización, el Partido Unión Revolucionaria, en cual se da tan controvertido artículo periodístico.

Dora Mayer, en 1934, colabora con un periódico orgánico del más ortodoxo fascismo que hubo en América Latina y con el de mayor impacto electoralmultitudinario, que le permitió quedar en segundo lugar en las elecciones de 1936, a escaso margen del candidato J.A Eguiguren, apoyado soterradamente por el Apra. En esas elecciones, anuladas arbitrariamente por el presidente Benavides, el candidato urrista Luis A. Flores, «Jefe Supremo del PUR», obtuvo el $29 \%$ mientras que J.A. Eguiguren llega al $37.1 \%{ }^{31}$.

Dora Mayer colabora con una poderosa organización político-fascista, heredera del sanchecerrismo y de su tiranía; organización que impuso toda una despiadada represión al Apra, en el contexto del debelamiento de su acción insurreccional en 1932. El PUR dirigido y reestructurado por su recio líder, Luis A. Flores, se sentía especialmente orgulloso. Dora Mayer no colabora simplemente con un periódico de derecha sino de la más extrema derecha que se ha registrado en la historia política del Perú, el fascismo urrista.

Al respecto, el PUR fascista en su extremismo de derecha fue muy claro en su perspectiva totalitaria en su proyecto corporativista, en su permanente elogio a Mussolini y a Hitler, en su denostación contra la democracia e incluso en sus afanes xenofóbicos y racistas contra la inmigración asiática en el Perú32. Esta era, pues, la organización política con la cual Dora Mayer colabora en 1934. Nada menos.

El periódico Crisol, en 1934, compartía con el periódico Acción, la condición de órgano del PUR. Y precisamente en ambos periódicos se puede apreciar la manera como el Partido Unión Revolucionaria, fundado por Sánchez Cerro el 30 de julio de $1931^{33}$, de conservador-populista, bajo el liderazgo de este comandante, deviene luego de su asesinato, el 30 de abril de 1933 en una organización políticamente fascista, bajo la dirección de Luis A. Flores pero manteniendo sistemáticamente la matriz carismática y arquetípica de Sánchez Cerro 34.

Ese carisma, que se mantuvo a pesar de su muerte, fue central en la relación que Dora Mayer estableció con el PUR bajo aquella colaboración periodística en Crisol. Tal relación debe ser destacada pues, en días previos, e inmediatamente posteriores a la colaboración de Dora Mayer en aquel pe-

\footnotetext{
Molinari, 2004, p. 541.

Molinari, 2004, passim.

T. Molinari, 1996

T. Molinari, 2004
} 
riódico, urrista, ya fascista, este publicaba comunicados orgánicos-fascistas esenciales del PUR. Por ejemplo, el 21 de abril de 1934 se publicaba: «Del Ideario del Partido. El nacionalismo auténtico» y el 30 de abril de ese año, conmemorando el primer aniversario del asesinato de Sánchez Cerro, Crisol publicaba «Del Ideario del Partido. Principios fundamentales» ${ }^{35}$.

Hay que precisar que la colaboración de Dora Mayer en el órgano de prensa urrista Crisol corresponde a un solo artículo aunque bastante largo. Es decir, no existe ni en Crisol - que circula en 1934- ni en Acción - que circula entre 1933 y 1936 - ni en los otros periódicos de coyuntura que saca el urrismo fascista, como La Batalla (1936), El Legionario, Órgano de la juventud fascista del PUR (1935) y UR, que circula en el contexto electoral de 1936, alguna otra evidencia de colaboración periodística de Dora Mayer con el PUR. ${ }^{36}$

Sin embargo, y no obstante que sólo fue un artículo con el que Dora Mayer colabora periodísticamente con el PUR- fascista, éste fue de alguna manera suficiente para demostrar en esos momentos una afinidad ideológica con el urrismo que incidía en la exaltación de Sánchez Cerro, en el ataque agudo al Apra, en la distancia esencial con el comunismo y en la denostación implacable al leguiismo. Para el PUR-fascista, las ideas que Dora Mayer expresa panorámicamente sobre la vida política del país, en esa colaboración, eran más que funcionales a su propia - y en esos momentos - emergente difusión doctrinaria. Dada la labor de propaganda abierta del urrismo y la propia condición sanchecerrista que el PUR-fascista seguía asumiendo en cuanto matriz arquetípica y carismática, Dora Mayer sabía perfectamente con qué tipo de prensa de partido estaba colaborando.

De allí que este personaje, por la fecha en que colabora en Crisol, de alguna manera se hacía co-partícipe de aquello que suponía la acción agresiva antiobrera de las milicias de camisas negras, la tan exaltada vanguardia de choque del urrismo fascista, la adhesión al corporativismo y totalitarismo mussoliniano, el elogio al propio Hitler, el odio apocalíptico al denominado "apro-comunisrno» e incluso a la campaña xenofóbica y racista que desplegaba el urrismo. Esa supuesta condición de «co-partícipe» de Dora Mayer frente a la acción del PUR-fascista no es mecánica ni tampoco inexorable, pero no deja de haber, en esos momentos, al menos, una sintonía política e ideológica lo suficientemente importante como para que Dora, sobre la base de su particular simpatía con Sánchez Cerro, llegue a colaborar con Crisol.

\section{2/ REVISTA DESOCIOLOGIA 25}


Además, fue un factor adicional para entender aquella sintonía políticoideológica, etc., el hecho que Abelardo Solís, importante estudioso y defensor de la comunidad indígena-campesina y, a su vez, ex contertulio en algunas ocasiones de J.C. Mariátegui en la década de 1920, junto a la propia Dora Mayer, sea en esos momentos no sólo activo militante urrista y destacado congresista sino, a su vez, secretario general del PUR fascista ${ }^{37}$.

Así, son varios los factores que arrastraron a Dora Mayer a ese «lado oscuro» de la política peruana, desliz que se concretó en esa colaboración periodística «efímera». Sin embargo, esta colaboración llevó a que, inevitablemente, Dora Mayer comprometiera su nombre y su prestigio intelectual, mezclándose, indirectamente, con un momento del periplo siniestro del fascismo peruano.

El artículo de Dora Mayer en Crisol se publica en la página 2 del miércoles 25 de abril de 1934 y fue recibido con mucho alborozo por el urrismo ${ }^{38}$. Veamos entonces tan controvertida publicación, cuyo elocuente encabezado es el siguiente:

-Formidable catilinaria de una escritora chalaca. Dora Mayer de Zulen enjuicia la realidad política del país con entera visión-

NUNCA HAN SIDO MUCHO LOS PERUANOS LOS QUE HAN INICIADO EL RENACIMIENTO DE UN PUEBLO ABATIDO

Dícese, aunque por supuesto o se puede garantizar la veracidad del rumor, que los leguiistas han ofrecido concluir con el cerrismo antes del 30 de abril próximo, primer aniversario del asesinato del presidente Sánchez Cerro.

El artículo 4 del acuerdo de Ginebra relativo a la cuestión de Leticia señala el 23 de junio próximo como término de expiración de los esfuerzos de la comisión de la Liga de las Naciones para arreglar el conflicto Perú-colombiano.

En junio deben realizarse las elecciones que complementando el personal de representantes al Congreso, restituyan al país la normalidad, estableciendo el orden bicameral conforme la nueva carta fundamental que nos rige.

Tres plazos están por cumplirse. Hablase de no efectuar las elecciones por hallarse el Estado embargado de hondos y peligrosos problemas insolutos. Una parte de la ciudadanía desea destruir a la otra y los rivales extranjeros están rondando ansiosos alrededor de las fuentes de la prosperidad nacional. He ahí la situación. 


\section{La lucha de los partidos}

Una infinidad de partidos y nada más que una sola idea: la de llegar al poder con el objeto de darse buena vida, de disponer del erario de la Nación y de figurar en los altos círculos sociales. La verdadera calidad de la especie se reduce a tres: conservadores, vanguardistas y patriotas. Los partidos fundamentales son cuatro: leguiistas, cerristas, civilistas y comunistas. Partidos capitalistas son leguiistas y civilistas: Partidos populares son comunistas y cerristas. Estos cuatro partidos representan en realidad cuatro principios distintos, mientras que los demás, con el Apra a la cabeza, no significan sino turbias combinaciones de aquellos mismos principios, aprovechados para fines oportunistas y personalistas.

\section{Leguía, leguiismo y leguiistas}

Leguiistas eran en 1919, legiones de obreros, de universitarios, de anónimos del gran público que se sentían cansados de muchas insuficiencias advertidas en los gobiernos que habían habido hasta entonces.

El pensamiento de las gentes estaba movido con las impresiones de la guerra europea. La plegaria de los soldados y de los pueblos sacrificados a los meros intereses de lucro de las clases dirigentes había desacreditado las leyendas del heroísmo guerrero e inmolación por la patria, la contemplación del fracaso de reyes, emperadores y zares, había socavado el respeto a rangos y categorías; se hizo la unión espiritual del proletariado mundial y la política de Wilson señalaba a Estados Unidos de Norteamérica como un Belén en que nacía un salvador.

Olvidando pronto lo mejor que se pensó antes del Tratado de Versailles, quedó en el ambiente un hollín cuan un cartón quemado que no había llegado a convertirse en diamante.

De ese ambiente de la época, cogió Leguía las pautas de su gobierno: la política de paz y de veneraciones para la potencia yanqui. Leguía hace un gobierno en favor de los ricos y de los extranjeros; con su método, una parte de la colectividad se beneficia demasiado y la otra sufre enorme desmedro.

Grandes sueldos, grandes monopolios, grandes peculados y grandes empréstitos succionan las rentas del fisco y aquella porción de los habitantes que no tienen la mamadera en las manos, perece a la fuerza de la carestía de las subsistencias y de la carga de los impuestos. Pues bien, en 1919 hubo ilusión por el candidato que el 4 de julio tomó por la razón y por a fuerza la silla presidencial. En 1929 era leguiista casi un 90\% de la población de la república, pero esta cantidad se descomponía así: unos que eran verdaderos correligionarios

\section{4/ REVISTA DE SOCIOLOGIA 25}


del mandatario, otros que se sentía adheridos al régimen como sanguijuelas al cuerpo cuya sangre chupan y unos terceros que no tenían de adherentes al dictador más que las circunstancias de servir en el régimen para ganarse el pan indispensable y carecer de libertar para expresar sus reparos privados.

Si de semejante manera, Leguía tenía infinidad de personas que dominaba con la sugestión de su personalidad y de sus propósitos o con el magnetismo de su dadivosidad o con la amenaza de sus iras, no es creíble que él pudiese haber caído en 1930 y que su caída pudiese haber producido tanto estrépito de imputaciones, si en su administración todo hubiera sido glorioso e inmaculado. Sólo el olvido, a que son tan propensas las masas, puede ser causa de que hoy sea posible intentar revivir los panegíricos que se fomentaba en días del oncenio y hace viable una nueva jornada del leguiismo.

\section{Sánchez Cerro, cerrismo y cerristas}

Sánchez Cerro fue un hombre que vino con la intención de practicar una administración honrada que el medio no le permitió hacer. Sánchez Cerro entretuvo un ensueño de libertador que abanicaba hasta Venezuela pero por ironía de la suerte, y no por una claudicación suya, le dio la semejanza de un tirano obligándolo a emplear medidas de represión contra la incesante ofensiva apro-leguiista.

Si Sánchez Cerro hizo promesas que no cumplió fue por equivocación pero no por un propósito deliberado de engaño al público. Sánchez Cerro a nadie odió como lo odiaron, a nadie difamó como lo difamaron. Procedía según los impulsos que le sugirieron los hechos, no sostenía teorías huecas en interminables conferencias o programas. El régimen de Sánchez Cerro es completamente distinto al de Leguía. El gobierno de Sánchez Cerro favoreció a las clases pobres. Y por eso este presidente se gana el cariño del pueblo. Comprende a cierto número de obreros, que pocos saben de cariño y mucho de mala política.

La integridad patriótica de Sánchez Cerro queda probada con la terminante resistencia que ofrece a las sugestiones del enviado de buena voluntad de Colombia, señor Laureano García Ortiz.

Alrededor de la personalidad definida de Sánchez Cerro se forma el cerrismo o sea la adhesión de los verdaderos peruanos a una figura que encierra ideales ausentes en los demás conductores que actúan en la política del país. El cerrismo se opone al antipatriotismo de los comunistas y la fastuosidad de los leguiistas que pueden acabar de sacrificar al país y a las masas a un delirio de grandeza. 
Pero un tercer factor después de Sánchez Cerro, lo constituyen los cerristas. ¿Cuáles en el partido son sanchecerristas de verdad y cuáles solamente se titulan cerristas sin abrigar principio típico alguno?

Si al fin del Oncenio 90\% de ciudadanos se habían sometido o vinculado al leguiismo, ¿con quien pudiera gobernar Sánchez Cerro sino con la mayoría de los ex-leguiistas que se le adhirieron para seguir lucrando o se disfrazaron para arruinarlo? Estos fueron en gran parte los «cerristas» que desacreditaron al régimen de los 17 meses. El clero fue, en términos generales, leguiistas. Los capitalistas debieron haber venido sobre Sánchez Cerro porque era una valla contra las rugientes huestes disociadoras. La colectividad anónima de la nación debiera haber sido una legión fiel a Sánchez Cerro, el único presidente, sin exceptuar a Billinghurst, que simpatizaba realmente con las clases menesterosas, pero hasta entre los anónimos hubo quienes despreciaron a dicho gobernante por ser sencillo y oscuro. iEs el colmo!

Tuvo que venir a raíz del crimen del hipódromo un régimen distinto. El gobierno de Benavides ha sido llamado con justificación un gobierno prudente. Todos se quedaron contentos porque se suspendía el esfuerzo de hacer patria. Son tantos los ciudadanos pe-ruanos envenenados con la propaganda comunista y tantos los deslumbrados con enormes proyectos de progreso material que la voz del patriotismo cae en el vacío. Después de ver la suerte que corrió Sánchez Cerro iquien iba a proponerse igual tarea que él? Aquél golpe de mano del 1 de septiembre de 1932 en Leticia no ha tenido tener como consecuencia para el país sino la humillación o la guerra. Hemos vivido con la prudencia diplomática un año más, pero el problema que nos confronta continúa el mismo. El cerrismo repudió la humillación, el comunismo repudió la guerra y así como por desgracia en el partido cerrista no todos son adictos a la memoria de Sánchez Cerro, quizás por felicidad no todos en el partido comunista y en el Apra son leninistas o marxistas absolutos. Apra, comunismo y leguiismo son iguales en perseguir fines económicos y no morales, únicamente el cerrismo de los cerristas de corazón contiene un idealismo patrio y una aspiración que no se confunde con ambiciones desorbitadas.

El cerrismo es la fórmula hecha para los que querrán ser y continuar siendo peruanos y el éxito de este partido depende del predominio que pueden adquirir en él los elementos legítimos sobre los ilegítimos.

\section{Los jefes muertos}

Muerto está Leguía y muerto Sánchez Cerro. De este hecho deducen alguno que un partido leguiista y un partido cerrista no tienen ya razón de existir. Pero

\section{6/ REVISTA DE SOCIOLOGÍA 25}


el espíritu de ambos hombres ha quedado suspendido en el ambiente. Leguía creó el objetivo de la política audaz que continúa palpitantemente: Sánchez Cerro condensó la réplica que persiste en su protesta. La masa movediza de los logreros ha abandonado el cerrismo en cuanto dejó de hallarse en el poder y el leguiismo gana cuerpo pues su programa deslumbra ofreciendo el dispendio inmediato de los ingentes recursos disponibles en materias primas y en el gozo propio a costa de las legiones que vengan atrás.

A pesar de que muchos afiliados que entran a un partido son más bien elementos adulterantes que integrantes, no se cierra el espíritu que a la agrupación ha infundido su primer jefe o el momento histórico que le dio el ser.

El leguiismo, el cerrismo, el civilismo, el comunismo y el aprismo semejan en verdad personalidades de caracteres diversos, por una de las cuales puede declararse las simpatías o antipatías más que por las otras.

\section{El espíritu de los partidos}

El cerrismo: Espíritu popular peruano: Sánchez Cerro mandó colocar la bandera nacional en los altos de las iglesias y presta un nuevo soplo de entusiasmo a la canción nacional. El cerebro de Sánchez Cerro piensa con la simplicidad de un niño en medio de diplomáticos, prelados y altos comerciantes que contienen, al presidente de los 17 meses, las manos empeñadas en deshacer la obra de Leguía.

El corazón de Sánchez Cerro, encerrado en palacio tras siete candados, late por los soldados en los cuarteles, por los pequeños vendedores en las calles y quisiera amparar a todas las víctimas del abuso. Sánchez Cerro rabia contra los demagogos de profesión que con tono insolente o intención artera le presentan pliegos reivindicativos para palanguearlo fuera del gobierno; él rabia contra el Apra cuyo espíritu es la antítesis del suyo, derecho, abierto y bondadoso él castiga la deslealtad con escupitajos, en quemante aunque ineficaz reemplazo de una sanción oficial.

Comunismo: Ojalá que hubiese sido un comunismo peruano, una discreta modernización del comunismo indígena que no reñía con los principios de religión y familia. Desgraciadamente el comunismo que ahora tenemos implantado en el país es un producto extranjero traído aquí por agentes pagados del erario de comerciantes rusos o yanquis. Desde los días del Oncenio se ve pasearse en nuestras ciudades y nuestros campos a tales agentes que en su mayoría llevan una vida inexplicable, perorando y agitando, trasladándose de un lugar a otro, en parte bien vestido sin trabajar, ni tener fuente conocida de entradas. Si ellos sacan el dinero para el sustento de sus mismos prosélitos, 
su profesión de propaganda es un excelente negocio y si perciben rentas de fuera del país representan una condenable intervención e intereses ajenos en nuestro medio. Este comunismo extranjero es temible por su espíritu de odio y de disociación. Este comunismo extranjero ha maleado lamentablemente a nuestras masas populares desviándolas del camino de una reforma patriótica que hace más de 20030 años idearían algunos de los intelectuales más rectos de nuestra propia raza.

El Apra: Esa improvisación de Haya de la Torre ha recogido en su espíritu todo el odio de los soviéticos y todas las venganzas del leguiismo. Y es por esta constitución y por el considerable número de sus adeptos un formidable peligro para el porvenir cultural y práctico de la república. Para las elecciones de 1931 se inscribieron en el partido aprista los leguiistas que no podían confesar su verdadera filiación durante la exaltación pública que siguió a la revolución de Arequipa, bajo el pretexto de que el gobierno de Sánchez Cerro fue una tiranía se fundió en el Apra una alianza leguiista-comunista, alianza absurdo, si se considera la discrepancia de los principios de los partidos que se reunían. El leguiismo comulga con el capitalismo y el imperialismo entonces ¿cómo podría comulgar el leguiismo con el aprismo? Probablemente los apristas intentarían negar dicha comunión pero a la vista está el testimonio de buena cantidad de periódicos notoriamente leguiistas o anticerristas en los cuales las figuras de Haya de la Torre y Leguía se presentan de brazo y celebran como suyo los éxitos favorables al Apra. Dignos de hojear son a este respecto las ediciones de «La Crónica», «El Callao», «El Comercio del Cuzco, Órgano del ex-ministro Escalante», etc., etc., en el período entre el 30 de abril de 1933 y la fecha actual. La llamada prensa aprista que fustiga sin cesar y acremente las tiranías y felonías cerrista es a su vez apañadora de tiranías y felonías leguiistas. Sus furores se dirigen contra el civilismo, sin mencionar en ninguna ocasión al leguiismo.

El Apra resulta así, a la larga, una tremenda farsa, sin que pueda admirar su completa falta de escrúpulos que le viene de ambos lados: el leguiismo y el comunismo cuya ideología es internacional y mercantil y cuyo lema es: «el fin justifica los medios». Para llegar al poder el Apra es sangre y lodo y las emplea con prodigalidad.

EL CIVILISMO: Este partido hizo gran daño al Perú entre 1860 y 1880; el civilismo derrochó la riqueza del guano que debiera haber servido para cimentar un magno Estado comercial cruzan el país de ferrocarriles, armado en defensa de la envidia de sus vecinos, sembrado de escuelas para la capacitación cívica de sus pobladores. Pero por la juventud de la república, por la

\section{8/ REVISTA DE SOCIOLOGÍA 25}


claridad del horizonte internacional de entonces, por la inexperiencia relativa de aquellos tempranos políticos, los errores y delitos cometidos fueron hasta cierto punto menos reprochables que los perpetrados durante el Oncenio. La soberanía del Perú no peligraba, la miseria no amenazaba a los habitantes. Un viejo y apto periodista, un antiguo demócrata pierolista y enemigo jurado del civilismo, descifraba en «Ecos de la Calle», del decano chalaco y con fecha 29 de junio de 1932, la situación en la época se remonta a los peculados del guano: «De 1860 a 1872, el crédito peruano tocaba el cielo con las manos de alto que estaba. La bolsa de Londres era una bolsa que nos metíamos en el bolsillo. En Londres nos hablábamos de tu con los norteamericanos. De igual a igual. De rico a rico y todo porque había unos señores Dreyffus hermanos y compañía que nos llevaban de la mano y nos tenían en la mano como eran los árbitros de nuestra riqueza y todos los poderosos, en virtud de sus tratos y contratos, por esos días éramos pues muchas cosas. Como guerreros les habíamos dado una tanda a la formidable flota española y como financistas teníamos unas montañas de guano capaces de servir de trinchera a un ejército de consignatarios y de fertilizar al desierto del Sahara. ¿Quien nos tosía? ¿Quién nos pisaba el poncho? Como que apenas les pedíamos dinero a los prestamistas, éstos nos daban a manos llenas y pedíamos y pedíamos sin tasas. Y nos enriquecíamos, es decir, se enriquecían los consignatarios famosos y mandábamos hacer ferrocarriles y comprábamos cuanto nos ofrecían los judíos más judíos que el mundo ha conocido. Echábamos la puerta por la ventana». Pues bien así han sido siempre de financistas los peruanos y así es de tener que serán en secula-seculorum por lo de «genio y figura hasta la sepultura». Pero hay que reconocer que de 1919 a 1934 el caso es más grave que de 1860 a 1880, porque ahora todo el mundo nos pisa el poncho, nuestra moneda está por los suelos y no tenemos recientes glorias guerreras. Tenemos si, pozos de petróleo tan hondos como altas eran las montañas de guano y tenemos otra vez contratistas y prestamistas que se encargaran de dejarnos en la ruina y tenemos más edad que en 1869 y que en 1879 . Y desde luego más responsabilidad y menos perdón ante la historia.

Aunque los civilistas serían por su idiosincrasia quizás completamente capaces de repetir su triste hazaña de hacer tres cuartos de siglo, ellos no han gobernado durante el Oncenio. Leguía se hizo simpático a las masas por combatir al civilismo. Leguía fue instigador de una intensa propaganda contra el civilismo que comenzó en el diario «El Tiempo» con las reseñas del abate Frías y que ha fructificado tanto que desde la revolución de Arequipa, el leguiismo puede lanzar-legiones de la clase media y el proletariado contra 
su rival político sin que alguien se diera cuenta del truco de prestidigitación que consiste en ocupar la atención del público con observar a los civilistas para no dejarlos ver lo que hacen los civilistas.

Que los comunistas ataquen a los partidos leguiista y civilista que son los representantes del capitalismo es justo, pero que los leguiistas mismos y los apro-leguiistas pongan en la picota al partido civil exhibiéndolo como objeto de la vindicta popular es un ardid inicuo, una mixtificación grotesca y da idea del juego con que se llega al público por caminos cuya dirección no se conoce.

Bien puede ser que el leguiismo hecha ya su obra de desmembración del territorio patrio, de desmoralización del ambiente general, de desculturización de la sociedad acabe en esta hora fatal por absorber el civilismo decadente; pero no cabe duda que José Pardo ha sido en su conducta más decente que Leguía, «El Comercio» mas decente que «La Prensa», el órgano adulón de la política del Oncenio, y el régimen de Sánchez Cerro bajo influencia civilista, superior a su antecesor en las facilidades otorgadas al pobre y en el resguardo de la dignidad nacional. ${ }^{39}$

En este larguísimo artículo, Dora Mayer descalifica con la más grave de todas las satanizaciones, al aprismo y al comunismo: con su supuesta colusión sinónimo en esos dramáticos momentos de la peor corrupción y el peor entreguismo. Dora Mayer, para quien Sánchez Cerro era una suerte de «niño santo», endilga al comunismo todas esas denostaciones, al igual que el fascismo urrista, en cuanto a aquella supuesta obra de agentes extranjeros y de promotores de odio empeñados maquiavélicamente en «intereses ajenos a nuestro medio». Ve al Apra, igual que el fascismo urrista como una suerte de fuerza corrupta aliada al leguiismo y al comunismo, dispuesta finalmente a la toma del poder «a sangre y lodo» y bajo el mismo odio supuestamente heredado de los soviéticos.

Dora Mayer aparece ya, en esos momentos, casi como una iracunda ideóloga que desde fuera del PUR y desde aquella singular sintonía sanchecerrista, no sólo coincide en aquellos aspectos centrales del urrismo fascista sino incluso parece influir en el propio fascismo urrista. Hasta su- «librepensamiento» cede, así, a «los principios de la religión y de la familia». Y en ese pragmático estereotipo «apro-comunista-leguiista», Dora Mayer va más allá de aquella sintonía sanchecerrista y se mimetiza con la perspectiva • política interna del fascismo urrista. Sintonía con el sanchecerrismo e influencia en el urrismo más que patética, dada su trayectoria intelectual-contestataria. Sin embargo,

\section{0/ REVISTA DE SOCIOLOGÍA 25}


no abandona, en lo esencial, aquella postura indigenista que probablemente la indujo paradójicamente, entre otros factores - como su rechazo frontal al leguiismo y sus agudos reparos frente al comunismo «no-indígena»- a ese chauvinismo «cerrista» en su derivación fascista.

¿Pero qué dice la propia Dora Mayer en sus Memorias sobre este episodio en su vida política intelectual? ¿Tuvo esto repercusión en su devenir intelectual?

Revisando el tercer tomo de sus Memorias, que parten de 1931 y se proyectan hasta la década de 1950 , es muy poco lo que dice sobre esos tan controvertidos vínculos. Sin embargo, da pistas que nos permiten de alguna manera acceder, desde su específica mirada desde finales de la década de 1950, a lo que implicaba la vida intelectual y política de Dora Mayer en los tempranos años treinta $4^{40}$. Es posible acceder, así, a su eclecticismo desde el cual se abría no sólo al sanchecerrismo sino, también, a su versión fascista.

De allí que enfatizando, reiterativamente, en su «no militancia política» Dora Mayer colaboraba periodísticamente sin que esto la obligase a mayores compromisos. No obstante, su simpatía con el sanchecerrismo era muy clara en 1934 y su marcada antipatía respecto al aprismo y comunismo también se hacía evidente en ese año de 1934. Desde lo cual y frente a estas divisiones políticas e ideológicas, irreconciliables, que arrastraban a multitudes en esos dramáticos años 30 en él Perú, Dora Mayer aparece sólo como simpatizante del sanchecerrismo. Ello se puede entrever en sus Memorias, donde claramente se acercó al sanchecerrismo y a su derivación fascista sólo hasta un límite: el que no le supusiese compromiso orgánico.

Sobre el fascismo condena la guerra desatada por el nazismo, repudia el racismo antisemita y cualquier forma de racismo, pero no es contundente en la condena política al régimen nazi como al fascista italiano. Es decir, en sus memorias, Dora Mayer rescata los «inicios» de ambos regímenes. Por lo que se puede apreciar en sus textos y en sus Memorias, jamás sucumbió al racismo y a la xenofobia, no obstante aquellas ambiguas actitudes que se han mencionado anteriormente, pues por su concepción indigenista el tema le resultaba hipersensible. Además, sus estrechas relaciones amicales con personajes judíos y asiáticos - o de origen asiático - en Lima, le despertaban más bien simpatías que la hacían inmune a cualquier forma de racismo. Su «amor loco» fue con Pedro Zulen, descendiente de chinos y de una tradición cultural que Dora Mayer respetó profundamente. Pero esto no implicó que 
rechazara los aspectos políticos-doctrinales, por ejemplo fascistas, que despertaban su interés. Precisamente, y por ello, esa tan complicada ambigüedad.

Algunos fragmentos de sus Memorias nos permiten acceder a esas entrelineas filtradas desde sus tan dosificados recuerdos. Así sobre Sánchez Cerro afirma:

... ha dado este presidente improvisado como muchos otros que figuran en la agitada historia de nuestra república el ejemplo de comprender que la primera exigencia en una sociedad de seres vivientes es que todos coman. ${ }^{41}$

Sobre sus vinculaciones con el «cerrismo», estas se hacen muy evidentes cuando, en relación al asesinato de Sánchez Cerro, dice:

Era el domingo 30 de abril. Al mediodía llegó Pancho el sobrino de la señora Rafaela, hospedado aquí y trajo la noticia de la tragedia en el hipódromo. Todo mi círculo era cerrista. Hubo una verdadera consternación. ${ }^{42}$

Pero, frente al devenir fascista de la Unión Revolucionaria apenas menciona con aire descriptivo los nuevos liderazgos y nada más. Ello dice muchísimo pues ante un personaje como Luis A. Flores, tan abierta y agresivamente fascista, como que no cabe la simple mención. 0 se le defiende, con las consecuencias que eso supone, o se le condena por lo que política e ideológicamente implicaba. Desde aquellos recuerdos dosificados, Dora Mayer no dice nada más; calla elocuentemente y hasta banaliza la géstica simbólica fascista del saludo levantando el brazo derecho y lo contrasta con el gesto simbólico aprista. Pero, al mismo tiempo, nuevamente filtra información sobre el tipo de amistades que frecuentaba en esos años. Ella dice lo siguiente,

... se encargan del sanchecerrismo huérfano, Luis A. Flores y Yolanda Coco. Flores tiene una casa política en Lima y otra en el Callao [...] surgió aquí la monada de levantar el brazo derecho en el partido de Sánchez Cerro y el izquierdo en señal de ser aprista. Como en broma levantaba yo alguna vez el brazo derecho al entrar en casa de una amiga cerrista y un día por distracción levante el brazo izquierdo causando espanto en la señorita que recibía mi visita. ${ }^{43}$

41 D. Mayer, Memorias..., t. 3, p. 16.

42 D. Mayer, Memorias..., t. 3, p. 17.

43 D. Mayer, Memorias..., t. 3, p. 17. 
Sobre el nazi-fascismo, con mucha ambigüedad, dice:

... Cristina Schereir continúa en su actividad política. En Alemania comienza a crecer el hitlerismo y le llegan volantes de ese partido que se supone sanamente renovador de la nación, abatida por la guerra de $1914 .{ }^{44}$

Y agrega páginas después:

... Hitler y Mussolini han principiado bien para acabar mal. La última carta de un jugador que parece hábil y admirable es la guerra. Cuidado con los nuevo Hitlers y Mussolini que pueden borrar con una mano lo que han erigido con la otra. 45

Ambigüedad que finalmente la lleva a afirmar

... el nazismo y el fascismo de Hitler y Mussolini son vencidos en seis años de guerra positiva, que hoy al cabo de seis años después de 1945, apenas tiene apagado su fuego latente, con una nueva constelación de pasiones. Ahora se trata de comunismo y democracia. Los ex-aliados están por luchar entre sí [...] por primera vez simpatizo, bajo esta situación con la gran potencia norteamericana, cuya soberbia siempre había levantado mi protesta..$^{46}$

Sobre tal ambigüedad y sobre aquel límite a sus vínculos con el sanchecerrismo que habían denotado sólo una «simpatía». Dora Mayer, de manera rotunda y de sus recuerdos dosificados dice:

... nunca he pertenecido a agrupaciones políticas, siempre he quedado afuera como mera simpatizante. Ni he podido darme por entero a ninguna facción ni estar del todo contra otra. Justamente por no haber en cualquier lado lo absolutamente bueno o malo. ${ }^{47}$

También en sus Memorias, ella insiste en su no-pertenencia a ninguna organización política y desde su condición de intelectual, dice,

... he estado siempre en mi carrera intelectualista de observadora de todos los tipos sociales. A ningún partido social he satisfecho, por no ser adherente incondicional y muchos no conciben que es realmente justo ser de todos y de ninguno o de ninguno y de todos..$^{8}$

\footnotetext{
44 D. Mayer, Memorias..., t. 3, p. 17.

45 D. Mayer, Memorias..., t. 3, p. 70.

46 D. Mayer, Memorias..., t. 3, pp. 43-44.

47 D. Mayer, Memorias..., t. 3, p. 17.

48 D. Mayer, Memorias..., t. 3, p. 48-49.
} 
Es visible como Dora Mayer se autopercibe como intelectual desde sus dosificadas Memorias. Y como intelectual asume y reivindica aquel eclecticismo político. Desde este parapeto reivindicativo de su condición, ella teje todo un manto de silencio sobre esa inocultable simpatía política que la llevó incluso a colaborar en 1934 con la prensa fascista-urrista. Más aún, desde aquella intensa sintonía, fue implacable en el ataque político al Apra y al partido comunista. Situación que no se puede borrar a pesar de sus dosificados recuerdos y de la reivindicación que hace de su condición de intelectual no integrada a ninguna «facción» política.

Sobre tal controvertida vinculación con el sanchecerrismo y en particular con su derivación fascista en 1934, ninguno de los autores que ha puesto de relieve su obra y su vida, ya sea directa o indirectamente, al tratar temas referentes al indigenismo o a la trayectoria de Pedro Zulen, dice algo sobre aquel desliz de Dora Mayer hacia ese «lado oscuro» y clamorosamente autoritario y reaccionario de la política peruana.

Magdalena Chocano, en su breve texto anteriormente citado, no dice nada sobre la especificidad de la sintonía de Dora Mayer con el sanchecerrismo, aunque tiende puentes para inferir este «deslizamiento» hacia aquel «lado oscuro», al enfatizar la distancia de esta intelectual con Mariátegui en el contexto del libro que Mayer escribió sobre el Oncenio. Al respecto y sobre aquel «desliz», nada hay en la biografía novelada de José Adolph sobre Dora Mayer, ni tampoco existe referencia alguna sobre esto en el libro de Wilfredo Kapsoli sobre el pensamiento de la Asociación Pro-Indígena ni en su artículo sobre Pedro Zulen. Finalmente, el silencio sobre aquello será el mismo en el prólogo que José Tamayo Herrera hace en el libro dedicado al pensamiento indigenista. Silencio similar al de Nicolás Lynch en su libro sobre el pensamiento social de la comunidad indígena a principios del siglo XX en el Perú y en el estudio de José Deustua y José Luis Rénique sobre intelectuales e indigenismo.

De esa manera, desde el silencio de los investigadores del indigenismo peruano y desde el propio y dosificado silencio de Dora Mayer en sus Memorias, ese «lado oscuro»-, intelectual y político, parecía inexistente. Sin embargo, y como vimos, existe la evidencia. De allí, que la condición de «intelectual» no exime de responsabilidades y menos si aquella colaboración fue con un periódico orgánico fascista.

\section{4/ REVISTA DE SOCIOLOGÍA 25}




\section{Referencias bibliográficas}

Escritos de Dora Mayer de Zulen

1908 Estudios sociológicos: el objeto de la legislación, escrito para el 40 Congreso Científico que sesionará en Santiago de Chile del 25 de diciembre de 1908 al 5 de enero de 1909. Callao: Imp. del H. Concejo provincial, $79 \mathrm{pp}$.

1914 La conducta de la Compañía Minera del Cerro de Pasco. Callao: Impr. del H. Concejo Provincial del Callao, $64 \mathrm{pp}$.

1921 El indígena peruano a los cien años de república libre e independiente. Lima.

1921 Un libro sobre Jesucristo. Crítica de la obra la «Locura de Jesús». Lima.

1924 La China silenciosa y elocuente: homenaje de la colonia china al Perú, con motivo de las fiestas centenarias de su independencia [28 de julio de 1921 - 9 de diciembre de 1924]. Lima: Renovación, 180 pp.

1928 Zulen y yo. Testimonio de nuestro desposorio ofrecido a la humanidad. Lima: Imprenta Garcilaso.

1929 El indígena y su derecho. Lima: Imp. J. Enrique Chenyek, 50 pp.

1932 El oncenio de Leguía. Callao, Tip. Peña.

1937 Temas actuales en el Perú y el mundo. Lima.

1938 El indígena y los congresos panamericanos: vicios viejos y miras nuevas en el Perú y en Sudamérica. Lima: Imp. Lux, 56 pp.

1950 Estudios sociológicos de actualidad. Colección de artículos. Callao, 112 pp.

1992 Memorias de Dora Mayer de Zulen. Lima: UNMSM, Seminario de Historia Rural Andina, 3 vol.

1993 La historia del mundo en un cascarón de nuez. Lima: UNMSM, Seminario de Historia Rural Andina, 60 pp.

- El deber pro-indígena: órgano de la Asociación Pro-Indígena. Publicación mensual doctrinaria. Lima.

Bibliografía consultada

Adolph, José (1989). Dora. Lima: Peisa.

BoBBı, Norberto (1988). «La duda y la elección. Intelectuales y poder», en La sociedad contemporánea. Barcelona: Paidós.

Bourdieu, Pierre (2000). Intelectuales, política y deber. Buenos Aires: Eudeba.

CAStillo OChOA, M. (1990). «El populismo conservador. Sánchez Cerro y la Unión Revolucionaría», en Adrianzen, Alberto. Pensamiento político peruano 1930-1968. Lima: Deseo, 410 pp. 
COSER, Lewis A. (1966). Hombres e ideas. El punto de vista del sociólogo. México: FCE. Chocano, Magdalena (1988). Ideas políticas de Dora Mayer. Lima: Cendoc, 30 pp.

DeUSTUA, José y José Luis RÉNIQUE (1984). Intelectuales, indigenismo y descentralismo en el Perú. 1897-1931. Cusco: Cera Las Casas.

GRAMSCI, Antonio (1981). La alternativa pedagógica. Barcelona: Fontanamara.

KAPSOLI ESCUdERO, Wilfredo (1987). «Pedro Zulen: el precursor», en Kuntur. Lima: Febrero.

KAPSOl ESCUdERO, Wilfredo (1980). El pensamiento de la asociación pro indígena. Cusco: Cera Bartolomé de las Casas, $151 \mathrm{pp}$.

MACERA, Pablo (1992). «Prólogo», en Memorias de Dora Mayer de Zulen. Lima: UNMSM, Seminario de Historia Rural Andina.

Molinari Morales, Tirso Aníbal (2004). La Unión Revolucionaria. 1931-1939. Una aproximación a la historia del fascismo en el Perú. Tesis de Maestría en Historia. PUCP, Lima.

Molinari MoRales, Tirso Aníbal (1996). La formación del Partido Unión Revolucionaria: crisis política y proceso electoral de 1931. Una aproximación al movimiento sanchecerrista. Tesis de Maestría en Sociología. PUCP, Lima.

LYNCH, Nicolás (1979). EL pensamiento social sobre las comunidades indígenas a principios del siglo XX. Cusco: Cera Bartolomé de las Casas.

Tamayo HerReRA, José (1981). El pensamiento indigenista. Lima: Mosca Azul.

SAID, Edward (1996). Representación del intelectual. Barcelona: Paidós.

WeBER, Max (1998). El político y el científico. Madrid: Alianza Editorial. 